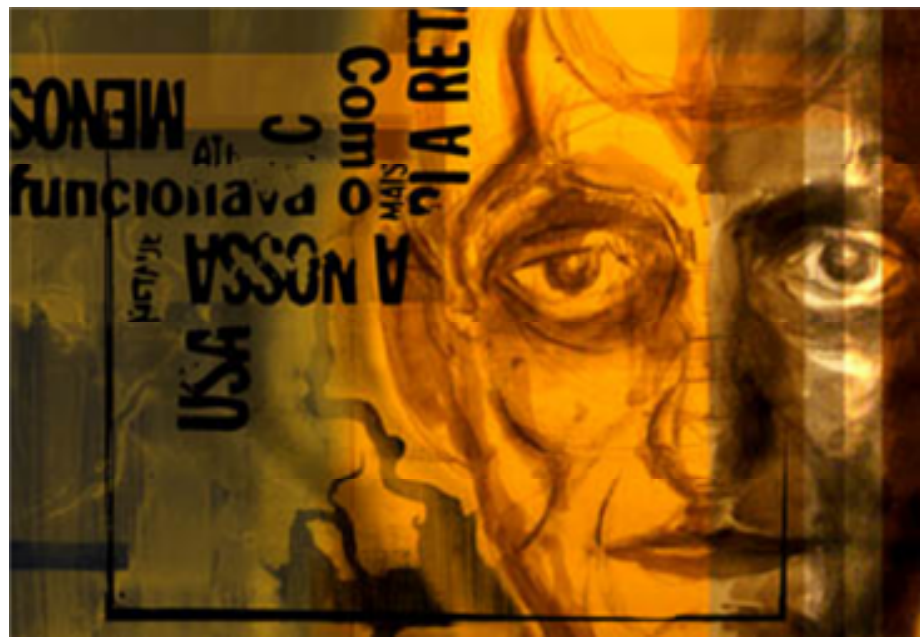

Ilustração Mario Vinicius Junior Silva

\title{
O imaginário na construção da realidade e do texto ficcional
}

\section{SANDRA DE PÁDUA CASTRO}

Graduada em Letras pelo Centro universitário de Patos de minas em 2002. Pós-graduada em Letras: Português e Literatura pela FIJ -RJ, em 2004. Atualmente, mestranda em Teoria da Literatura com a linha de pesquisa, Literatura e outros sistemas semióticos, desenvolvimento um trabalho sobre o teatro de Albert Camus.

\section{Resumo}

Neste artigo, tendo como base os estudos de Wolfgang Iser, almejou-se identificar a função do imaginário e dos textos ficcionais na constituição das sociedades e da vida humanas. Por uma visão do texto ficcional além de determinações que poderiam reduzi-lo à mera cópia, este texto buscou romper a dicotomia ficção/realidade, realçando a interdependência desses conceitos. Para isso, foi efetuada uma analogia entre o processo de criação textual e de leitura e o processo de realização do imaginário como fundamento da realidade.

Palavras-chave: imaginário, realidade, ficção. 
Cumpre esclarecer que, para que ocorra a aceitação, precursora da compreensão da existência de um imaginário deflagrador de concretizações tanto na ficção quanto na realidade, há que se romper, como afirma Wolfgang Iser(1) com "o saber tácito [...] que opõe realidade e ficção". Essa certeza da oposição, originada do que se vê como óbvio, tem raízes profundas na herança platônica e numa modernidade que divisava "luzes" unicamente na razão e declarava o imaginário como uma instância constitutiva de irrealidades, ficção e sonho.

"Três vezes afastadas do ser, aparências e nunca realidades", a ficção é ainda considerada, por Platão, nociva ao homem e à república ideal. Conforme consta no Livro $\mathrm{X}, 603 \mathrm{~b}$ de $A$ República, este filósofo considera que toda arte imitativa "executa suas obras longe da verdade e, além disso, convive com a parte de nós mesmos avessa ao bom-senso, sem ter em vista, nesta companhia e amizade, nada que seja são ou verdadeiro". No entanto, o próprio Platão abre espaço, após expulsar os poetas de sua cidade imaginária, àqueles "seus defensores que não forem poetas, mas forem amadores de poesia", para que pleiteiem sua causa em prosa e mostrem que ela "é não só agradável, como útil, para os Estados e a vida humana" (2).

Para responder a Platão e expor meios e fins da ficção à vida humana, não há como prescindir de uma redefinição dos efeitos do imaginário sobre a realidade e da ficção como realização e trânsito do imaginário. Isso é o que se pretende com este trabalho.

Ao contrapor realidade e ficção, retira-se o que uma significa para a constituição da outra, mutuamente. Não se pretende, ao retirar a oposição, igualar quixotescamente as duas instâncias. Realidade e ficção não são opostos, mas são diferentes, interdependentes, complementares e, principalmente, intercambiáveis. Segundo Iser, o que realiza a relação entre ficção e realidade é o imaginário, através de atos de fingir, que transgridem os limites de uma e outra e do próprio imaginário. É pertinente uma breve análise do conceito dessas instâncias para que possamos entender como se relacionam e a importância disso para os "regimes políticos e para a vida humana".

- imaginário, até então concebido como aquilo que existe apenas como produto da imaginação que é considerada uma "faculdade criativa do pensamento pela qual este produz representações de objetos inexistentes, não tendo, portanto, função cognitiva"(3), não poderia despertar interesse para estudo em uma época que se fecha em comprovações científicas para determinação de verdades. Cornelius Castoriadis considera "espantoso que a imaginação [...] descoberta e discutida pela 
primeira vez há vinte séculos por Aristóteles" não tenha adquirido seu lugar central na filosofia da subjetividade e que o "imaginário social, imaginário radical instituinte, [tenha sido] totalmente ignorado ao longo da história do pensamento filosófico, sociológico e político"(4). O que assombra Castoriades aconteceu também ao longo dos estudos sobre a literatura, fato ainda mais surpreendente, uma vez que esSa é uma instância privilegiada de recortes, condensações e verbalizações do imaginário.

Para Iser, experimentamos o imaginário de modo difuso, informe, fluido e sem um referencial específico que 0 objetifique. Mas, apesar de sua existência no estado difuso, ele é a condição para superar o existente e projetar o ainda inexistente. O Imaginário é similar a um espaço aberto que, sem indicar limites, permite a invenção do possível como prenúncio de uma outra realidade. Também Castoriadis afirma que, somente "porque há imaginação radical e imaginário instituinte, que há para nós realidade, e esta realidade"(5).

O que é a realidade? No dicionário, aquilo que existe efetivamente. E "efetivamente" quer dizer realmente, ou seja, que existe de forma real, verdadeira. Fôssemos nos limitar a um pensamento dicionarizado, seguiríamos perguntando até o fechamento do círculo tautológico. Mas o real, que neste estudo refere-se ao mundo extratextual, é apontado como "tudo que pode ser apreendido na sua concretude" ou até mesmo como "aquilo que se nos apresenta com as feições do verdadeiro, provável, plausível e acreditável"(6). Caímos assim em questões subjetivas, dependentes da capacidade de apreensão de algo como concreto e acreditável, por um ou mais indivíduos, para que este algo se torne real ou irreal, pertencente ou não ao que admitimos como realidade. Schütz afirma que "somos propícios a pensar de modo diferente sobre o mesmo objeto e podemos escolher qual o modo de pensar a que queremos aderir e qual ignorar. A origem e fonte de toda realidade, [...] sempre está, portanto, em nós mesmos"(7). A partir dessa afirmação podemos presumir a existência de várias realidades na formação de uma realidade social, cultural, nacional, planetária...

Entretanto, somos racionalistas o suficiente para exigir provas que ratifiquem ou não a existência de algo como real, para admitirmos este algo como nossa realidade ou o habitante dela. Há, ainda, para corroborar a dificuldade da afirmação do que seja realidade, a questão do poder; a questão da sobreposição de realidades conforme interesses dos dominantes: as realidades instituídas. Se o que denominamos realidade é, como disse Castoriadis, produto do imaginário, é sobre este que o poder atua. O imaginário é a instância onde se projetam, criam e também se forjam realidades. Nesse sentido, podemos abstrair a definição de realidade como algo construído de 
acordo com uma intencionalidade de um indivíduo ou de uma coletividade que detenha um poder para tal a partir de uma seleção naquilo que é difuso do imaginário. E que definição é essa, senão a anteposta por Iser para a ficção? "A ficção é a configuração do imaginário"(8). É isso: ficção e realidade são formadas do mesmo material do imaginário e a realidade não é apreendida e sim construída, numa dinâmica incansável com o imaginário.

Diante de tal constatação, para não nos assemelharmos a Dom Quixote e tomarmos qualquer bacia como sendo o elmo de Mambrino, faz-se necessária uma definição mais pormenorizada da ficção e da relação desta com a realidade, pois existe uma fronteira entre elas que é "uma questão heurística e dependente da relação entre os membros de um grupo social"(9). Convencionaremos doravante, juntamente com Iser, a tratar o ficcional como o mundo do texto e a realidade como o mundo extratextual.

A ficção, de acordo com Iser "provém do ato de ultrapasse das fronteiras existentes entre o imaginário e o real, mas mantém uma diferença constante quanto a eles [...], adquire predicados da realidade e guarda os predicados do imaginário"(10). Ela transgride os limites entre uma e outra através de atos de fingir. O autor escolhe, sem regras prévias, elementos do real, "de natureza sócio-cultural ou mesmo literária", e nesses seleciona os que serão transladados e utilizados na ficção. O método, aparentemente simplista, pode nos conduzir ao equívoco da existência de uma mera cópia. No entanto, essa cópia dobra-se, curva-se à força do imaginário, e a seleção operada não se repete única nem passivamente no texto. Ao selecionar, campos são demarcados e trazidos à percepção. O que antes residia inerte, tomado como a própria realidade, é perspectivado "através da divisão destes campos de referência em alguns elementos que são atualizados pelo texto, enquanto outros permanecem inativos"(11). A seleção opera, portanto, a percepção de partes alterando a visão do todo; o todo do texto e o todo da realidade.

Pelo ato de fingir, a realidade é repetida no texto e transformada em signo de uma outra coisa. O imaginário configura-se por essa transformação. No texto ficcional, resultado das transgressões, é irrealizada a realidade e realizado o imaginário. Segundo Iser, as transgressões de limites provocadas pelo ato de fingir "representam a condição para a reformulação do mundo formulado, possibilitam a compreensão de um mundo reformulado e permitem que tal acontecimento seja experimentado"(12). 
Antes de adentrarmos no terreno da experiência da recepção proporcionada pelo texto ficcional, o como se, vejamos como aqueles elementos selecionados, agora transgredidos, agem no mundo do texto, para que assim possamos visualizar, por analogia, a ocorrência no mundo extratextual.

Assim como, por atos de fingir, ocorre seleção e transgressão, também os elementos selecionados e transgredidos continuarão a selecionar e a transgredir na medida em que se associem com outros elementos. Essa segunda etapa de transgressão e de atuação do imaginário, agora configurado e reconfigurando-se, é chamada por Iser de combinação. O texto passa a ser o crisol que, pela química do imaginário, reposiciona e ressemantiza os elementos. Ao se combinarem, criam "relacionamentos intratextuais", abrindo novas perspectivas com os elementos não escolhidos para a associação. De acordo com a intencionalidade do texto, "cada relação estabelecida altera a faticidade dos elementos e os converte em posições que obtêm sua estabilidade através do que excluem"(13).

O que observamos, na descrição da construção do texto efetuada por Iser, é uma repetição da forma inicial de seleção, utilizada pelo autor da ficção em graus maiores de complexidade. Na primeira seleção, elementos escolhidos e não escolhidos estão, perspectivamente, no espaço da escrita e do real. A partir da segunda seleção, que é a combinação, estão, devido aos relacionamentos intratextuais, no espaço da escrita e da não-escrita ou do dito e do não-dito. Ambos os espaços, na sua complexidade, são apreendidos pelo leitor na medida em que o texto se denuncia, se desnuda, "se dá a conhecer como ficcional"(14).

Iser vê esse desnudamento da ficcionalidade, oriundo de "convenções determinadas, historicamente variadas, de que o autor e o público compartilham"(15), como peculiar à ficção literária. O desnudamento é, portanto, o traço distintivo entre a ficção textual e as outras ficções extratextuais, cuja existência é "importante tanto nas atividades do conhecimento, da ação e do comportamento, quanto no estabelecimento de instituições, de sociedades e de visões de mundo"(16). É devido a essa peculiaridade que o texto ficcional posiciona o leitor entre o mundo que foi referência para a ficção, o mundo "real" e o mundo representado, que não é e nem representa o mundo, mas o perspectiviza, cria contrastes, descortina a percepção e induz à comparação, ao como se.

o leitor, suspenso entre seu próprio mundo e um outro que é como se fosse, ou poderia ou deveria ser, vive a experiência do não-ser, a experiência de irrealizar-se e, provisoriamente, realizar-se num outro. O mundo do texto possibilita "que por ele sejam vistos os dados do mundo empirico por uma ótica que 
não lhe pertence"(17), mas que poderá pertencer ao leitor após a experiência.

o texto, que se configurou pela realização do imaginário, passa a requerer de seu leitor a capacidade de produzir o objeto imaginário por ele realizado; e o leitor o faz, da mesma forma que o autor, através de atos de fingir, pois, de acordo com Luiz Costa Lima, "só conseguimos entrar em comunicação com o ficcional quando aprendemos a vê-lo como um todo que reclama o nosso imaginário"(18). O leitor penetra, pelo imaginário, também no que não foi dito. Conforme Ricouer, citado por Iser, no texto, o sentido é captado e o significado absorvido no "momento em que o leitor adota o sentido, isto é, quando $O$ sentido age sobre a existência, produzindo efeitos"(19) .

Agindo sobre o leitor, o ficcional, como trânsito do imaginário, atua também na realidade circundante do próprio leitor. O fragmento selecionado da realidade, até então estranho ou fora da percepção do leitor, uma vez que se encontrava imerso na suposta realidade, ganha, pelo imaginário, um novo enfoque que também, e sobretudo, coloca em foco o não-selecionado e o não- dito. É a experiência do nãodito que configura, no ser e na realidade, o imaginário. Conforme Iser,

a formulação do não-formulado abarca a possibilidade de nos formularmos e de descobrirmos o que até esse momento parecia subtrair-se à nossa consciência. Neste sentido, a literatura oferece a oportunidade de formularmo-nos a nós mesmos, formulando - não dito [...] de constituirmos a nós mesmos constituindo uma realidade que nos era estranha.(20)

O mundo ficcional é uma oportunidade para romper os horizontes limitados de expectativas que o leitor possa ter do texto, do mundo extratextual e de si mesmo. Ao romper limites, o mundo ficcional amplia o espaço que ele mesmo preenche, para ser novamente rompido. O mundo textual, dessa forma, torna-se um dinamizador do mundo extratextual. A república de Platão ou qualquer outra estaria condenada à inércia e, conseqüentemente, à morte, não fosse pela existência desse habitante.

Pudemos verificar o processo da constituição do texto ficcional e sua importância, viabilizada pela leitura, na formação da subjetividade e, conseqüentemente, na construção e na transformação das realidades e do conhecimento. A leitura é condição essencial para a realização do imaginário e para a irrealização das realidades que se tornam nocivas à comunidade dos homens. Nesse contexto, o ensino de leitura é primacial para a formação de leitores ativos que possam agir, tal como o "contra-herói" citado por Roland Barthes, em 0 prazer do 
texto(21), invertendo o mito bíblico e criando uma "Babel feliz".

\section{Abstract}

On this article, having as basis Wolfgang Iser's studies, it was longed to identify the function of imaginary and the fictitious texts in the constitution of the societies and the human beings' life. For a vision of literature beyond determination that could reduce it mere copy, this text searched to breach the dichotomy fiction/reality, enhancing the interdependence of these concepts. For this an analogy was effected between the process of literary creation and reading and of accomplishment of the imaginary one basis of the reality.

Key-words: imaginary, reality, fiction

\section{Notas}

(1) ISER, 1996. p.13.

(2) PLATÃO, $607 e$.

(3) JAPIASSU, 1991. p. 129.

(4) CASTORIADIS, 1999. p.241.

(5) CASTORIADIS, 1999. p.242.

(6) ROMERO, 1997. p.44.

(7) LIMA, 1983. p.191.

(8) ISER, 1983. p.379.

(9) PINTO. http://www.filologia.org.br/soletras/9/01.htm.

(10) COSTA LIMA, 1983. p.379.

(11) ISER, 1996. p.17.

(12) ISER, 1996. p.16.

(13) ISER, 1996. p.20.

(14) ISER, 1996. p.23.

(15) ISER, 1996. p.23.

(16) ISER, 1996. p.25.

(17) ISER, 1996. p.28.

(18) COSTA LIMA, 1984. p.61.

(19) ISER, 1996. p.81. 
(20) ISER, 1999. p.82-93.

(21) BARTHES, 1973. p.8.

\section{Bibliografia}

REFERÊNCIAS BIBLIOGRÁFICAS CASTORIADIS, Cornelius. A instituição imaginária da sociedade. Trad. Guy Reynaud. Rio de Janeiro: Paz e Terra, 1982.

- Feito e a ser feito: as encruzilhadas do labirinto V. Trad. Lílian do Valle. Rio de Janeiro: DP\&A Editora., 1999.

ISER, Wolfgang. O ato da leitura. Trad.Johannes Kreschmer. São Paulo: Ed. 34,1999 . Trad. Luiz Costa Lima. In: COSTA LIMA, Luiz. Teoria da literatura em suas fontes. V.II. Rio de Janeiro: Francisco Alves, 1983.

- Problemas da teoria da literatura atual: o imaginário e os conceitos-chaves da época. Trad. Luiz Costa Lima. In: COSTA LIMA, Luiz. Teoria da literatura em suas fontes. V.II., Rio de Janeiro: Francisco Alves, 1983.

- O fictício e o imaginário. Perspectivas de uma antropologia literária. Trad. Johannes Kretschmer. Rio de Janeiro: Eduerj, 1996.

JAPIASSU, Hilton e MARCONDES, Danilo. Dicionário básico de filosofia. Rio de Janeiro: Jorge Zahar Editor, 1991.

JAUSS, Hans Robert. A história da literatura como provocação à teoria literária. São Paulo: Ática, 1994.

LIMA, Luiz Costa. O controle do imaginário. Razão e imaginação no Ocidente. São Paulo: Ed. Brasiliense, 1984.

PINTO, Marcelo de Oliveira. A escrita de histórias de literatura e a questão da realidade. Disponível em http://www.filologia.org.br/soletras/9/01.htm. Acesso em 08/07/05.

PLATÃo. Diálogos III: A República. Trad Leonel Vallandro. Rio de janeiro: Ediouro, s/d.

ROMERO, Emílio. O inquilino do imaginário. Formas de alienação e psicopatologia. São Paulo: Lemos Editorial, 1997.

SCHÜTZ, Alfred. Dom Quixote e o problema da realidade. Trad. Lima, L.C. In: CostA LIMA, Luiz. Teoria da literatura em suas fontes. v.II. Rio de Janeiro: Francisco Alves, 1983. 